\title{
A VOZ E O GESTO NOS DESENHOS DE ANTONIN ARTAUD
}

\author{
André Silveira Lage*
}

Resumo: Este texto propõe uma análise do último projeto de livro de Antonin Artaud, escrito em 1948 e intitulado 50 Dessins pour assassiner la magie [50 Desenhos para assassinar a magia]. A partir desse livro, trata-se de pensar a relação entre texto e imagem, mas também entre a voz e gesto como elementos primordiais e constitutivos dessas duas práticas: escrever e desenhar.

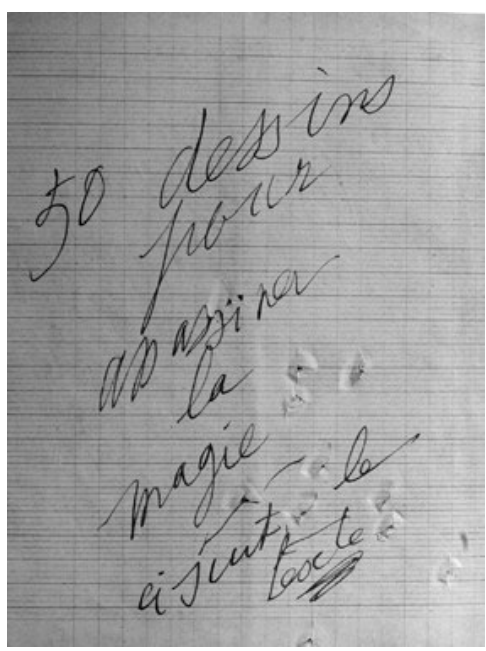

Poeta maldito, encarnação máxima da potência do gênio romântico, profeta da Beat Generation, porta-voz do movimento antipsiquiátrico, teórico do Teatro da Crueldade, ator iluminado, revoltado e louco, Antonin Artaud (1896-1948) é, sem dúvida, uma das referências mais requisitadas pelo pensamento crítico e pela criação artística contemporânea. Sua obra fascinou várias gerações e não cessa de nos fascinar, tanto pela sua complexidade quanto pelo impacto considerável que

* Pós-Doutorando do Pós-Lit/UFMG. Bolsista da Fapemig. 
ela teve e continua a ter no pensamento contemporâneo. Revolucionária e inovadora, ela marcou uma geração de atores e encenadores (Julien Beck, Judith Malina, Tadeusz Kantor, Peter Brook, Robert Wilson) e contribuiu na formação do pensamento crítico de grandes teóricos franceses do século XX (Maurice Blanchot, Jacques Derrida, Michel Foucault, Gilles Deleuze). Híbrida e multifacetada, ela ocupa uma posição radicalmente singular: no entrecruzamento da literatura, do desenho, do teatro, do cinema e do rádio.

Nesse imenso espectro de textos, cores, sons, imagens, movimentos e gritos que constituem a obra de Antonin Artaud como um todo, escolhemos como corpus de estudo uma parte pouco conhecida de sua obra no Brasil, a saber, seu último projeto de livro, escrito no asilo de Ivry-sur-Seine, pouco tempo antes de sua morte, em 1948, intitulado 50 Dessins pour assassiner la magie [50 Desenhos para assassinar a magia]. Trata-se de seu último projeto de livro associando textos e imagens, o qual nasceu de um convite de Pierre Loeb, que lhe sugeriu, como ele mesmo o indica, "uma obra sobre os curiosos desenhos que vemos freqüentemente na margem ou no texto mesmo de seus últimos cadernos ". ${ }^{1}$

50 Dessins pour assassiner la magie se insere no contexto desses inumeráveis Cabiers $^{2}$ que foram incessantemente

\footnotetext{
${ }^{1}$ LOEB. Dessinateur et critique, p. 63-64. Pierre Loeb acolheu também em sua galeria a exposição Portraits et Dessins par Antonin Artaud, de 4 a 20 de julho de 1947.

${ }^{2}$ A partir do anos 1980, esses cadernos foram publicados pelas edições Gallimard e ficaram conhecidos sob o nome de Cabiers de Rodez et Cabiers de Retour à Paris [Cadernos de Rodez e Cadernos do Retorno à Paris]. Os Cabiers de Rodez (tomo XV a XXI das Obras completas) reúnem cronologicamente os cadernos escritos por Artaud de fevereiro de 1945 a maio de 1946, data de sua saída de Rodez. Os Cabiers de Retour à Paris (tomos XXII à XXV) reúnem os cadernos escritos de junho de 1946 a janeiro 1947. Os cadernos, redigidos a partir dessa data até a morte de Artaud, no dia 4 de março de 1948, não foram ainda publicados. Paule Thévenin foi a responsável pelo deciframento, pela transcrição, pela transmissão e edição desses cadernos, que se encontram
} 


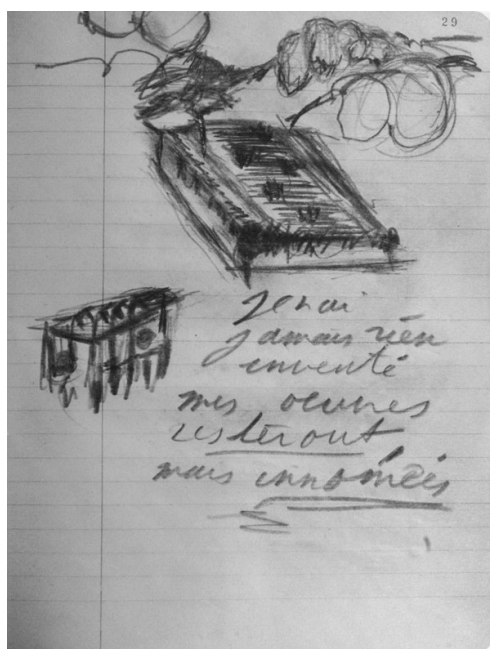

desenhados e escritos por Artaud, de 1945 - quando estava ainda internado no asilo de Rodez - até os últimos anos de sua vida. No entanto, sua morte, no dia 4 de março de 1948, interrompeu e inviabilizou a sua publicação. Somente agora (quase cinquenta anos após a sua morte), temos acesso ao projeto de Artaud, pois 50 Dessins pour assassiner la magie foi recentemente publicado pelas edições Gallimard numa bela edição que reuniu em um único livro: um prefácio que introduz o leitor na trama da escritura e do desenho, as reproduções fac-símiles do manuscrito original do texto 50 Dessins pour assassiner la magie, uma retranscrição colocada em paralelo e uma compilação de reproduções fac-símiles intitulada Dessins pris à des cabiers de notes [Desenhos extraídos de cadernos de notas]. ${ }^{3}$

A primeira questão que surge ao nos depararmos com esses Dessins pris à des cabiers de notes é a seguinte: como devemos lê-los? Ou ainda: que tipo de relação se estabelece entre a escritura e o desenho? Sabemos que se trata de cadernos nos quais Artaud esboça textos, rememora sonhos, procura escansões visuais ou

atualmente na seção de Manuscritos Modernos da Biblioteca Nacional Francesa, em Paris. Podemos encontrá-los reproduzidos parcialmente e em fac-símile em diversos livros ou catálogos de exposicão. Ver o livro de Paule Thévenin e Jacques Derrida, Antonin Artaud: dessins et portraits, o catálogo Euvres sur papier da exposição realizada no Musée Cantini, e mais recentemente, o catálogo da exposição Antonin Artaud realizada na Bibliothèque Nationale de France (de 7 novembro a 4 fevereiro de 2007).

${ }^{3}$ Os desenhos escolhidos para acompanhar essa edição de 50 Dessins pour assassiner la magie foram publicados segundo a ordem de sua aparição nos 12 cadernos retidos por Artaud para esse projeto. 
sonoras, dispersa por acaso pedaços de frases, acumula sequências sonoras, alinha exorcismos, uma fórmula conjuratória, uma litania de glossolalias e, ao mesmo tempo, rabisca, desenha incansavelmente objetos indecifráveis, blocos, caixas, caixões, pregos, pedaços de membros, fragmentos de rostos, barras, pontos, manchas, formas informes. Eis aí uma das características principais desses cadernos: a imbricação entre a escritura e o desenho. Ocupar o espaço da "página" desses cadernos com diferentes modos de expressão, saturá-lo de signos verbais e não-verbais, habitá-lo com desenhos informes, rabiscos e anotações, tudo isso é uma maneira de combinar estes dois gestos - escrever e desenhar. No entanto, é raro que os desenhos venham ilustrar, figurar o que o texto diz. Nem ornamento, nem ilustração, eles introduzem, ao contrário, uma mesma pulsação, uma mesma respiração, cuja "força de dilaceramento" seria idêntica à da escrita. Essa "força de dilaceramento", que está em ação tanto nos seus desenhos quanto na sua escritura, traduz o que Jacques Derrida chama de "pensamento do lance", que é o "pensamento da pulsão mesma, da força pulsiva, da compulsão e da expulsão. Da força antes da forma". ${ }^{4}$

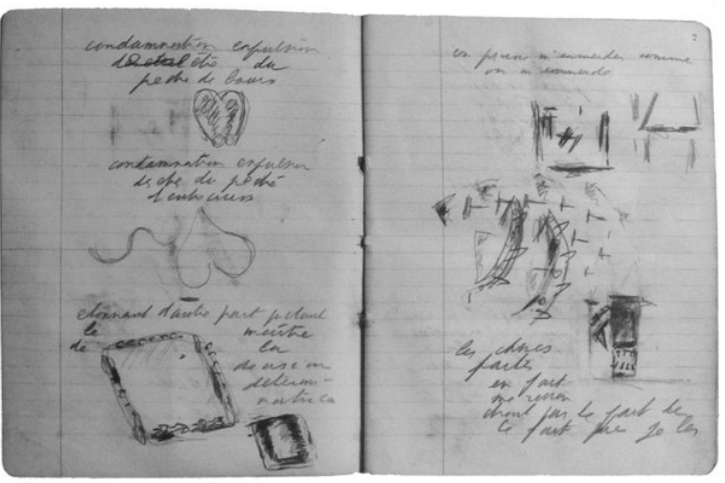

Do mesmo modo, o manuscrito do caderno contendo o texto 50 Dessins pour assassiner la magie se inscreve nessa mesma perspectiva de um "pensameto do lance" do qual fala Derrida. Trata-se de um manuscrito impregnado e atravessado pelo impulso do lançamento, do projétil, e este se verifica nas marcas da perfomance da qual procede o manuscrito: martelado com a ajuda

\footnotetext{
${ }^{4}$ DERRIDA; BERGSTEIN. Enlouquecer o subjétil, p. 43.
} 
de um instrumento pontiagudo, ele é perfurado em diversos lugares, formando, visualmente, sobre a página do caderno, uma constelação de pequenos furos que aparecem desde a primeira página, atravessando e repetindo-se em todas as outras. Podemos analisar esses furos, essas pequenas perfurações como as marcas do gesto físico e vocal que os precedem, e seria difícil lê-los sem pensar no papel da dicção, da declamação e da escansão que lhes são indissociáveis. Na página manuscrita não há nenhum desenho, mas, paradoxalmente, o desenho está ali, ele habita a página, traça um pensamento sob a forma de explosões de subjetividade, de blocos de sopro que disseminam, na página impressa, sua natureza essecialmente vocal. Em outras palavras, enquanto marca, figura e traço do gesto físico e vocal que os engendram, esses furos são o desenho. E são eles que nos conduzem a pensar a noção de voz não somente como uma oralização da escritura,

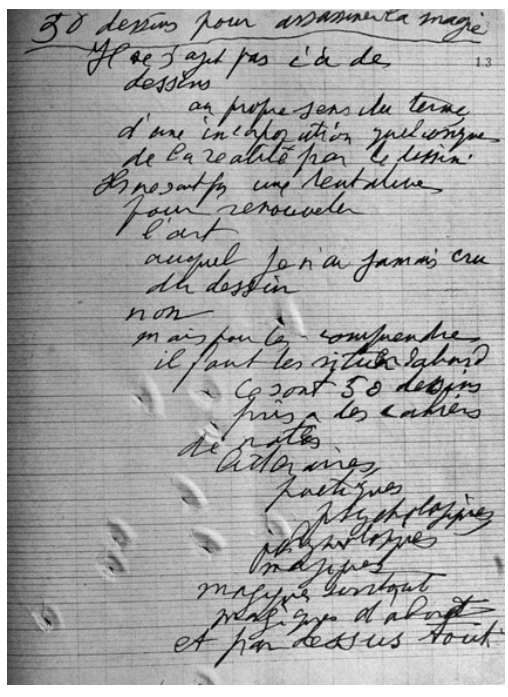
mas também como um campo de forças impregnado na letra, no traço escrito e desenhado, rompendo assim com a concepção tradicional que opõe a voz à letra, o vocal ao escriptural e ao visual.

Quanto ao texto propriamente dito de 50 Dessins pour assassiner la magie, a primeira impressão que se tem é a de que ele foi escrito de um só golpe, em um único gesto. A própria grafia de Artaud nos sugere tanto a velocidade 5 de uma escritura que segue o impulso do pensamento quanto

\footnotetext{
${ }^{5}$ Lembremos também que a velocidade foi, no tempo do surrealismo, dos champs magnétiques [campos magnéticos] e dos desenhos automáticos de André Masson, um fator determinante.
} 
uma forma de escritura arcaica, pictográfica, na qual as letras são percebidas de maneira plástica e como desenho.

Há nesse texto um pensamento contaminado pelo desenho. Mas escrever sobre os seus desenhos não significa descrevê-los formalmente, nem usar de um saber enciclopédico para interpretá-los. O que Artaud faz é de outra ordem. Desde a primeira frase do seu texto, ele exprime a sua posição em relação aos seus desenhos e reivindica, para eles, um estatuto que escapa da lógica da representação, do mundo da arte e da própria ideia de "desenho":

\author{
Il ne s'agit pas ici de \\ dessins \\ au propre sens du terme, \\ d'une incorporation quelconque \\ de la réalité par le dessin. \\ Ils ne sont pas une tentative \\ pour renouveler \\ l'art \\ auquel je n'ai jamais cru \\ du dessin \\ non. ${ }^{6}$
}

Mais longe, ele martela a sua recusa: "Ce ne sont pas de dessins / ils ne figurent rien, ne défigurent rien." Ou ainda: "ils ne veulent rien dire, ils ne représentent / absolument rien." Como nos sugere

\footnotetext{
${ }^{6}$ ARTAUD. 50 Dessins pour assassiner la magie, p. 16. Os trechos aqui traduzidos tentam "se aproximar" do original em francês, o tanto quanto possível. Traduzilos foi um grande desafio não desprovido de impasses, dificuldades, hesitações, indecisões, próprias à experiência ou à travessia da tradução. Nas citações mais longas, reproduzimos também a diagramação do texto original. "Não se trata aqui de / desenhos / no sentido próprio do termo, / de uma incorporação qualquer / da realidade pelo desenho. / Eles não são uma tentativa / de renovação / da arte / na qual nunca acreditei / do desenho / não."

${ }^{7}$ ARTAUD. 50 Dessins pour assassiner la magie, p. 20, 24. "Não são desenhos, eles não figuram, não desfiguram", eles "não querem dizer nada, não representam absolutamente nada."
} 
Artaud, trata-se de pensar seus desenhos não como um espaço de representação, mas muito mais como um campo de forças, ou simplemente como "notas" (no sentido musical e verbal do termo), ou ainda, "comme des corps de sensibilité nouveaux" que se arremessam da página escrita e que ele designa também sob o termo de trumeaux [tremós]:

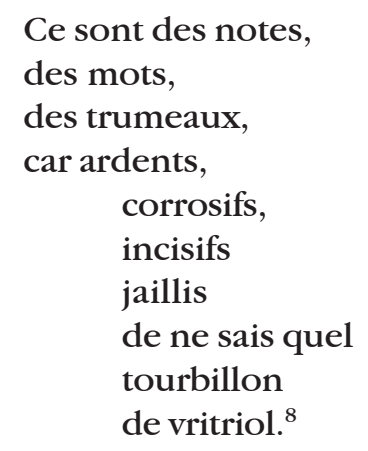

Entenda-se, nessas palavras e em tremós, o seguinte sentido: "Tremó do frâncico thrum: pedaço, toco e, também, pernil de porco na terminologia de carniça. Os tremós seriam então as palavras dos corpos escorchados, partidas em toco, pedaços de corpos transfigurados em signos," como sublinha Évelyne Grossman. ${ }^{9}$ Essa fragmentação se verifica na própria maneira de dispor as palavras sobre a página, isto é, verticalmente e utilizando o espaço da linha minimamente, preenchendo-o com recorrência com uma única palavra. Essa ruptura com a linearidade do discurso, essa utilização do espaço da linha, privilegia a poesia em detrimento da prosa. Trata-se de um procedimento que possibilita dar ênfase para a visualidade da palavra e que desloca, ao mesmo tempo, o

\footnotetext{
${ }^{8}$ ARTAUD. 50 dessins pour assassiner la magie, p. 20. "São notas, / palavras, / tremós / pois ardentes, / corrosivos / incisivos, / brotam de não sei qual / turbilhão / de vitríolo."

9 Ver ainda nesse mesmo texto os desdobramentos de sentido da palavra "tremós". (GROSSMAN. Prólogo, p. 23-24).
} 
movimento da leitura: não mais da esquerda para a direita, mas sobretudo de cima para baixo. Mas, paradoxalmente, essa fragmentação, essa ruptura, é também uma unidade não fragmentada, uma frase jorrada de uma só “lance”, em um só golpe.

Artaud afirma ainda que:

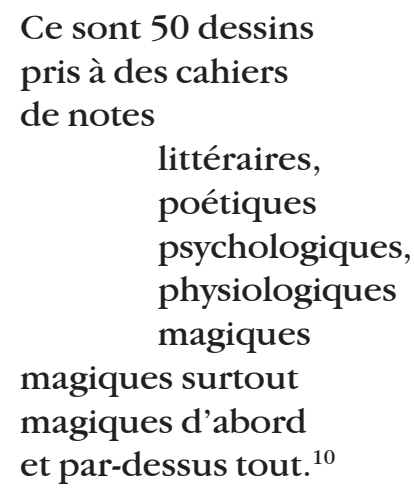

Precisemos o que ele entende por "magia", para evitar como nos sugere Évelyne Grossman - "a chata circularidade dos comentários imaginários de noções imaginárias (Artaud e a Cabala, Artaud e os Tarots, a astrologia, a alquimia etc.)". ${ }^{11}$ É verdade que Artaud manifestou ao longo de sua vida uma insaciável curiosidade pelos saberes ocultos, acumulando durante anos uma quantidade impressionante de leituras sobre as religiões orientais, as práticas esotéricas, os rituais mágicos, os tratados de alquimia. Inútil portanto considerar esses textos como fontes de inspiração. O interesse de Artaud pela magia se situa em um outro plano. Desvinculado-a da significação ocultista que lhe é frequentemente atribuída, a noção de magia em Artaud é pensada por Évelyne Grossman como um "elo", uma "potência de comunicação" cuja eficácia leva a "curar

\footnotetext{
${ }^{10}$ ARTAUD. 50 dessins pour assassiner la magie, p. 16. "São 50 desenhos / extraídos de cadernos / de notas / literárias / poéticas / psicológicas / fisiológicas / mágicas / mágicas sobretudo / mágicas antes de tudo / e acima de tudo."

${ }^{11}$ GROSSMAN. Prefácio, p. 5. (Tradução minha)
} 
esta difícil cisão, esta ruptura entre as coisas e as palavras, as idéias e os signos, esta separação entre a cultura e a vida, esta petrificação mortífera que Artaud vê em obra no mundo ocidental". ${ }^{12}$

Enquanto "elo", "potência de comunicação", a "magia" traz também à tona a questão da eficácia da linguagem, do poder do signos e das imagens. Ela designa a capacidade da arte de captar "as forças que dormem em todas as formas" e agir diretamente sobre a sensibilidade do público (leitor ou espectador). ${ }^{13}$ Ela diz respeito à vida das formas, ao poder que a arte tem de captá-la e dirigi-la aos nossos sentidos. É por isso que, em Artaud, a arte se confunde com a magia. Aliás, não seria o teatro um duplo da magia ${ }^{14}$

Desde os seus primeiros manifestos do Théâtre Alfred Jarry [Teatro Alfred Jarry] (1926-1929), ${ }^{15}$ Artaud já sublinhava os poderes específicos de ação do teatro, definindo-o como uma "verdadeira operação de magia". ${ }^{16}$ No livro Le théâtre et son double [O teatro e seu duplo] (1938), ele se refere a uma utilização mágica do espaço, reivindincando mais uma vez o "elo" entre aquilo que até então se encontrava separado: ator e público, autor e encenador, linguagem sonora e linguagem visual, gestos, movimentos, gritos, luzes: "É sob esse ângulo de utilização mágica e de bruxaria que se deve considerar a encenação." 17 Tudo o que diz respeito às entonações, ao trabalho da dicção, à sua ação dissociadora e vibratória sobre a sensibilidade, ao seu poder de expansão e de

\footnotetext{
${ }^{12}$ GROSSMAN. Prefácio, p. 6. (tradução minha)

${ }^{13}$ ARTAUD. O teatro e seu duplo, p. 6.

${ }^{14}$ Interessante notar que a palavra "magia" é, na língua francesa, anagrama da palavra "imagem" (magie/image).

${ }^{15}$ Fundado em 1926 por Antonin Artaud, Roger Vitrac e Robert Aron, o Teatro Alfred Jarry - como o nome já o explicita - é uma homenagem ao mestre da patafísica ["a ciência das soluções imaginárias"], ao inventor de Ubu Rei e precursor do teatro Dada.

${ }^{16}$ ARTAUD. O teatro e seu duplo, p. 30.

${ }^{17}$ ARTAUD. O teatro e seu duplo, p. 81.
} 
difusão no espaço, tudo issso indica que a magia em Artaud releva de uma experiênca orgânica com a linguagem considerada "sob a forma do Encantamento". ${ }^{18}$

Eis aí um ponto fundamental de sua teoria do teatro que será retomado em 50 Dessins pour assassiner la magie, a saber, "la valeur plastique / objective du souffle":

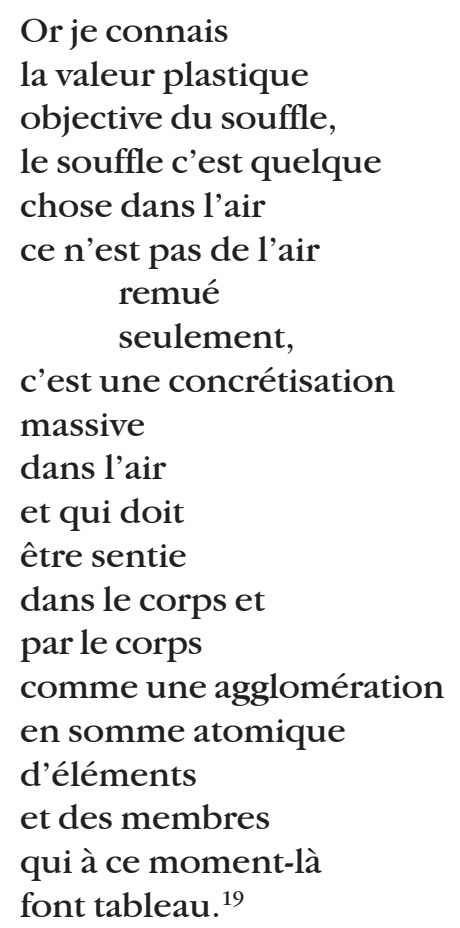

Lembremos que no seu Teatro da Crueldade, Artaud já afirmava que um dos meios privilegiados sobre os quais repousa

\footnotetext{
${ }^{18}$ ARTAUD. O teatro e seu duplo, p. 47.

${ }^{19}$ ARTAUD. 50 dessins pour assassiner la magie, p. 32, 35. "Ora conheço / o valor plástico / objetivo do sopro, /o sopro é algo / no ar / não é o ar / remexido / apenas, / é uma concretização / massiva no / ar / e que deve / ser sentida / no corpo e / pelo corpo / como uma aglomeração / em suma atômica / de elementos / e de membros / que neste momento / formam um quadro."
} 
o trabalho do ator é o sopro, o sopro como um fluxo de energias, como uma emissão de forças, como uma "aglomération atomique" capaz de unir o interior e o exterior, o físico e o mental. Textos como "O teatro de Séraphin" e "Um atletismo afetivo" 20 são também poemas sobre a função mágica do sopro e da voz, cujos postulados serão incansavelmente praticados por Artaud durante a sua estadia em Rodez e até os últimos anos de sua vida. Nesse sentido, o sopro como temática recorrente em Rodez está relacionado com o trabalho do ator, mas há também uma grande diferença que é preciso pontuar, pois Artaud desloca a prática do ator de seu contexto cênico, atribuindo-lhe um outro sentido e um outro valor: o ator aqui em questão não é um comediante, ele não utiliza seu corpo para construir uma personagem, não se inscreve no espaço da representação. Ao contrário, ele age com seu corpo para devolver o corpo ao corpo. Isto é, ele age com o seu corpo para concretizar o que Artaud nomeia "une certaine opération de transmutation physiologique, et de métamorphose organique vraie du corps humain". ${ }^{21} 50$ Dessins pour assassiner la magie se inscreve nessa perspectiva de uma reinvenção anatômica que passa pelo corpo, pelo ritmo, pela voz, pela explosão desse "verbe vibratoire, systématique et méthodique" 22 que coloca o teatro dentro do corpo e que faz do corpo humano o lugar privilegiado do ato teatral. ${ }^{23}$

Mas qual seria a relação entre esse "valor plástico e objetivo do sopro" e a prática do desenho? A minha hipótese é a seguinte:

\footnotetext{
${ }^{20}$ Ver esses textos em: ARTAUD. O teatro e seu duplo, p. 151-160, 167-173.

${ }^{21}$ ARTAUD. 50 dessins pour assassiner la magie, p. 1.547."Uma certa operação de transmutação fisiológica, e de metamorfose orgânica verdadeira do corpo humano."

${ }^{22}$ ARTAUD. CEuvres complètes, p. 240.

${ }^{23}$ Podemos ouvir a força explosiva desse "verbo vibrátil, espasmódico e metódico" na sua famosa emissão radiofônica Pour en finir avec le Jugement de dieu [Para acabar com o Julgameno de Deus], de 1947.
} 
desenhar em Artaud é um corpo-a-corpo com a questão da língua. Desenhar não significa representar por traços alguma coisa, é submeter a língua a uma espécie de torsão e de escansão que engaja o corpo inteiro:

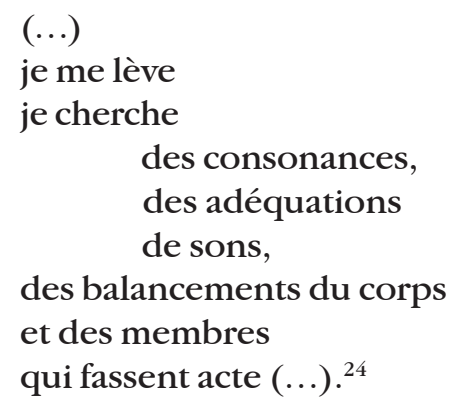

Escandir, lembremos, consiste em decompor a língua em elementos constitutivos através da voz, em analisá-la mesmo. É uma antiga prática da declamação da poesia por meio da qual se faz sobressair o corte das sílabas em unidades métricas. Mas Artaud vai muito mais longe. Escandir pode também ser compreendido como uma eletrocução que Artaud inflige à língua, como uma corrente de eletricidade vocal que produz o que a poesia escrita não é capaz de dizer: um ritmo, uma acentuação, uma respiração, uma melodia cujas modulações sonoras são minuciosamente experimentadas e estudadas com precisão, com esse "rigor implacável"que fundamenta uma de suas definições da Crueldade. ${ }^{25}$

${ }^{24}$ ARTAUD. 50 dessins pour assassiner la magie, p. 31. “(...)/ levanto-me / procuro / consonâncias, / adequações / sons, / balanços do corpo / e dos membros / que reproduzam o ato (...)."

${ }^{25}$ A teoria do Teatro da Crueldade em Artaud foi muitas vezes mal compreendida, torturada, maltratada, pois foi confundida com um teatro de sangue, com exposição de órgãos, mal físico, tumulto e sadismo. Em diversos textos do Teatro e seu duplo, Artaud tenta explicar o que ele entende por "crueldade", concebendo-a não "no sentido episódico, acessório, por gosto sádico e perverso de espírito, por amor dos sentimentos estranhos e das atitudes malsãs," mas no "sentido de apetite de vida, de rigor implacável, no sentido 


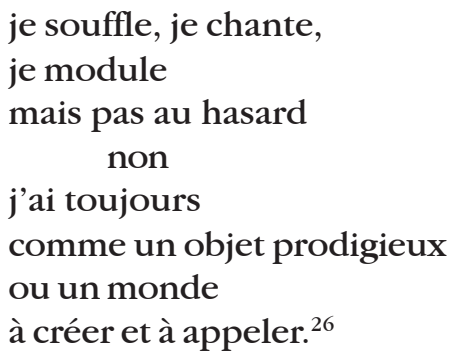

Explorar as potencialidades sonoras da língua, fazer ouvir tanto a palavra organizada com vistas a um sentido lógico quanto o fonema puro, sua explosão e seu nascimento, são operações indissociáveis de uma oralidade e de uma gestualidade que presidem e constituem como tal essas duas práticas que se contaminam reciprocamente, o desenho e a escritura. Ou seja, ambas as práticas remetem à intensidade de uma ação, ao mesmo tempo gestual evocal:

\author{
Mes dessins \\ sont purement \\ et simplement la \\ reproduction sur le \\ papier \\ d'un geste \\ magique \\ que j'ai exercé \\ dans l'espace vrai \\ avec le souffle de mes \\ poumons
}

\footnotetext{
de turbilhão de vida que devora as trevas". Fica claro que a crueldade em questão não é física, nem moral. Ela é, antes de tudo, vital - intimamente ligada ao próprio princípio da vid : "Tudo que age é uma crueldade. Disse crueldade como poderia ter dito vida." (ARTAUD. O teatro e seu duplo, p. $133,118,119,134)$. Sobre essa questão da crueldade, ver meu artigo"O teatro segundo Artaud: ou a reinvenção do corpo", p. 62-71.

${ }^{26}$ ARTAUD. 50 dessins pour assassiner la magie, p. 31-32. "Eu sopro, / canto, / modulo / mas não por acaso / não / tenho sempre / como que um objeto prodigioso / ou um mundo / para criar e para chamar."
} 


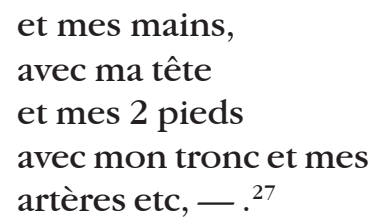

Lembremos que, nos últimos anos de sua vida, Artaud tinha o hábito de exercer o golpear de seu sopro, utilizando simultanea-mente um martelo que ele batia sobre um grande tronco de madeira. Essa atividade lhe permitia experimentar as modulações de sons, as vibrações de cada sílaba, os diferentes ritmos da matéria verbal. Numa carta de setembro de 1945 endereçada à Roger Blin, Artaud escreve:

Un de mes moyens est de chanter des phrases scandées en écrivant comme d'autres chanteraient 'viens poupule ou au près de ma blonde' et l'autre moyen de frapper des coups avec mon souffle dans l'atmosphère et ma main comme on manie le marteau ou la cognée pour faire jaillir des âmes sur mon corps, et dans l'air. ${ }^{28}$

O que era para Artaud uma maneira de dizer o texto poético, de fazê-lo "sortir de la page écrite" como num desejo de capturar a palavra em seu nascimento, era normalmente confundido pelos médicos dos hospitais psiquiátricos com delírio desenfreado, histeria verborrágica, alienação mental. Numa carta a Jean Paulhan,

\footnotetext{
${ }^{27}$ ARTAUD. 50 dessins pour assassiner la magie, p. 27, 28. "Meus desenhos são puramente / e simplesmente a reprodução no / papel / de um gesto / mágico / que exerci / no espaço verdadeiro / com o fôlego de meus / pulmões / e minhas mãos / com minha cabeça e meus 2 pés / com meu tronco e minhas / artérias etc., -."

28 "Um de meus recursos é cantar frases escandidas quando escrevo, como outros cantariam 'viens poupoule ou auprès de ma blonde' e outro recurso é golpear com meu sopro a atmosfera e minha mão, tal como se maneja um martelo ou uma foice para fazer jorrar almas sobre meu corpo e o ar." ARTAUD. Euvres complètes, p. 119.
} 
ele precisa: "Je suis toujours ici en danger d'être traité en fou et en agité lorsque je travaille ici, soit en gestes, soit en chants, soit en marches, soit en attitudes à mon athlétisme affectif." 29 Tais médicos desconheciam que essas operações eram uma maneira de fazer viver no exterior, "dans l'atmosphère", tudo o que o texto escrito congela, fixa, petrifica.

"Sortir de la page écrite", experimentar a eficácia de uma "action qui a eu réellement lieu", ação que é essa "matière électrique" que "naît instantanément dans le corps," tal é a aventura que nos propõe Artaud nesse texto. Isto é, uma aventura que nos ensina que há uma maneira de ler em que não apenas os olhos e os ouvidos são solicitados.

Résumé: Ce texte propose l'analyse du dernier projet de livre d'Antonin Artaud, écrit en 1948 et intitulé 50 dessins pour assassiner la magie. A partir de ce livre, il s'agit de penser le rapport entre le texte et l'image, mais aussi entre la voix et le geste comme éléments primordiaux et constitutifs de ces deux pratiques: écrire et dessiner.

\section{Referências}

ARTAUD, A. CEuvres complètes. Paris: Gallimard, 1961. Tomo II

ARTAUD, A. CEuvres complètes. Paris: Gallimard, 1974. Tomo XIII

ARTAUD, A. CEuvres complètes. Paris: Gallimard, 1974. Tomo XI

ARTAUD, A. Euvres sur papier. [Catálogo da exposição do Musée Cantini]. Marseille: Néotypo, 1995.

29 "Estou sempre aqui em perigo de ser tratado de louco e de agitado quando trabalho aqui, seja em gestos, seja em cantos, seja em caminhadas, seja em atitudes do meu atletismo afetivo." ARTAUD. Cuvres complètes, p. 127. 
ARTAUD, A. O teatro e seu duplo. Trad. Teixeira Coelho. São Paulo: Martins Fontes, 1999.

ARTAUD, A. 50 dessins pour assassiner la magie. [Édition établie et organisée par Évelyne Grossman]. Paris: Gallimard, 2004.

ARTAUD, A. CEuvres. Paris: Gallimard, 2004.

ANTONIN ARTAUD. [Catálogo da exposição da Biblioteca Nacional Francesa]. Paris: Gallimard, 2006.

DERRIDA, J.; BERGSTEIN, L. Enlouquecer o subjétil. Trad. Geraldo Gerson de Souza. São Paulo: Editora Unesp, 1998.

GROSSMAN, É. Prólogo. In: ARTAUD, A. Van Gogh, o suicida da sociedade. Trad. Ferreira Gullar. Rio de Janeiro: José Olympio, 2003.

GROSSMAN, É. Prefácio. In: ARTAUD, A. 50 dessins pour assassiner la magie. Paris: Gallimard, 2004.

LAGE, A. O teatro segundo Artaud: ou a reinvenção do corpo. Revista FIT 3 [Festival Internacional de Teatro]. Belo Horizonte: Rona Editora, 2008. p. 62-71.

LOEB, P. Dessinateur et critique. Cabiers Renaud-Barrault, número "Antonin Artaud", p. 63-64, 1969. 